\title{
Soil-water retention of highly expansive clay stabilized with a bio- polymer
}

\author{
Diego Manzanal ${ }^{1,3^{*}}$, Sandra Orlandi ${ }^{1}$, Mariano Fernandez, ${ }^{2}$, Cecilia Laskowski ${ }^{1}$, Juan Cruz Barría ${ }^{2}$, Mauro Codevila ${ }^{2}$, \\ and Teresa Piqué ${ }^{2}$
}

${ }^{1}$ Universidad Nacional de la Patagonia San Juan Bosco, Argentina.

${ }^{2}$ Facultad de Ingeniería, Universidad de Buenos Aires (UBA), Argentina.

${ }^{3}$ Universidad Politecnica de Madrid (UPM), España

\begin{abstract}
The unpredictable expansiveness of clayey soils due to the change of water content can be responsible for significant pathologies on civil infrastructure. This behaviour depends mainly on the physical and chemical characteristics of the clayey soil and the stress-suction state of the soil. Extensive research has been carried out to control the swelling potential of clayey soils with traditional inorganic additives such as lime and cement. However, the use of these stabilizers presents adverse implications in terms of cost and environmental impact. Bio-products and waste by-products are an environmentally friendly alternative for geotechnical soil stabilization. In this article, we assess the effect of lignin on the hydro-mechanical behaviour of highly expansive clay. The research focuses on the behaviour upon wetting and the soil-water retention properties of clay and lignin-treated clay with different percentages. Suction measurements were made by using the filter paper technique. Particular emphasis on the mercury intrusion porosimetry analysis of the untreated and treated CR-Clay is done. Results of CR-Clay with lignin-based stabilizer show significant reduction of swelling upon wetting for the higher percentage of addition. Increase of the aggregation is observed with the growth of lignin percentage. An analysis of the soil-water retention properties with the vanGenutchen model is presented.
\end{abstract}

\section{Introduction}

Moisture variations due to wetting and drying cycles of clayey soils composed by smectite-type minerals can produce volumetric changes that could generate significant pathologies in structures or civil constructions. Several authors have studied natural soils treatment with traditional inorganic additives such as lime or cement, to reduce the swelling potential of expansive clays (p.e. Hoyos et al.[1]). However, the use of these stabilizers presents adverse implications in terms of cost and environmental impact [2]. In particular, these kinds of additives increase soil $\mathrm{pH}$ affecting groundwater quality. In recent years, Latin America has implemented new bioeconomy concepts based on bio-fuels and bio-products production (Sasson and Malpica, 2018, Orlandi et al. 2020). Several authors have studied different products derived from biomass as soil stabilizers, such as $\beta$-glucan [3], chitosan [4], power and ash rice $([5,6]$, seeds and starches [7]), olive waste [8], and tree resins [9], among others.
The effect of green additives on the properties of clayey soils depends mainly on the soil-additive interaction and the physico-chemical characteristics of the additive. One of these green additives is lignin. It is a polyphenolic biopolymer, obtained as by-products in pulp and paper industries. All around the world, the paper pulp industry produces vast quantities of lignin, and its disposal has become a global ecological problem $([2,10])$.

Lignins are a non-toxic compound in comparison with lime or cement [11]). Indraratna et al. (2008) reported that lignins reduce the coefficient of soil erosion and significantly increased the critical shear stress of a silt clay soil. Recently, several authors focused their studies on the reduction of the swelling capacity of high expansive clays (Alazigha et al., [2,11]; Fernandez et al., $[12,13]$; Orlandi et al $[14,15,7]$. However, the unsaturated behaviour of clay -lignin require more attention. In this work, we studied the behaviour of compacted samples of clay and lignin-treated clay upon wetting, the analysis of microstructure with MIP and SEM and the soil-water retention properties.

\footnotetext{
* Corresponding author: diego.manzanal@gmail.com
} 


\section{Materials}

A natural clayey soil (CR-Clay) from Comodoro Rivadavia, Chubut, Argentina and Calcium Ligonoslfonate (CLS) bioproduct were used.

\subsection{CR-clay: Patagonian expansive selected soil}

CR-clay comes from a near-surface layer of a stronglyfissured formation. Manually extracted samples were obtained in the form of irregular blocks at a depth of 0.50$2.20 \mathrm{~m}$ from open pits located in Comodoro Rivadavia City. Then, they were air-dried, pulverized and sieved through the \#10 ASTM sieve. Table 1 shows physicochemical properties of CR-Clay, such as the particle size, the index properties (LL, PL, PI, shrinkage limit, SL; specific gravity, Gs) following ASTM standards, the mineralogy by XRD, sulphate concentration, specific surface area, Se; and Cation Exchange Capacity, CEC $[4,7,16]$. The predominant cation is $\mathrm{Na}+$, although $\mathrm{Ca} 2+, \mathrm{Mg} 2+$ and $\mathrm{K}+$ are also present. The clay has a relatively low sulphate concentration $(3608 \mathrm{ppm})$. The specific surface of Clay, measured using the maximum adsorption of methylene blue, is higher than $563 \mathrm{~m} 2 / \mathrm{g}$. According to the Unified Soil Classification System (USCS), Clay is classified as MH.

CR-clay is a soil with a high swelling potential, mostly composted by smectite. In natural conditions, its natural moisture is nearby $18 \%$.

Table 1. CRclay properties.

\begin{tabular}{cc}
\hline properties & CRclay \\
\hline \% clay & 76.6 \\
\hline \% mood & 21.4 \\
\hline \% sand & 1.96 \\
\hline Textural class & clay \\
\hline Liquid limit, LL & 74.5 \\
\hline Plastic index, PI & 35.3 \\
\hline shrinkage limit, SL & 24.2 \\
\hline SUCS & MH \\
\hline RX mineralogical identification & $100 \%$ smectite \\
\hline Specific surface area $[\mathrm{m} 2 / \mathrm{g}]$ & 563 \\
\hline $\mathrm{SO} 4-[\mathrm{mg} / \mathrm{kg}]$ & 3608 \\
\hline $\mathrm{Ca}[\mathrm{meq} / 100 \mathrm{~g}]$ & 16.0 \\
\hline $\mathrm{Mg}[\mathrm{meq} / 100 \mathrm{~g}]$ & 1.5 \\
\hline $\mathrm{K}[\mathrm{meq} / 100 \mathrm{~g}]$ & 7.8 \\
\hline $\mathrm{Na}[\mathrm{meq} / 100 \mathrm{~g}]$ & 28.5 \\
\hline $\mathrm{CEC}$ & 55
\end{tabular}

\subsection{Calcium LigonosIfonate - CLS}

CLS is brownish powder lignin from calcium and sodium sulphite process (L4) provided by Norlig (Argentina). Some physicochemical characteristics of the product, provided by the manufacturer, are listed in Table 2 .
Table 2: Technical report. CLS composition.

\begin{tabular}{cccc}
\hline Analysis description & Unity & $\begin{array}{c}\text { Technical } \\
\text { specification }\end{array}$ & $\begin{array}{c}\text { Typical } \\
\text { values }\end{array}$ \\
\hline $\mathrm{pH}(10 \%$ solution$)$ & {$[\%]$} & $3.0-4.5$ & 3.8 \\
\hline Moisture (at $\left.105^{\circ} \mathrm{C}\right)$ & {$[\%]$} & Max. 8.0 & 6.0 \\
\hline Ashes (at $\left.800^{\circ} \mathrm{C}\right)$ & {$[\%]$} & Max. 10.0 & 7.7 \\
\hline Calcium (as Ca) & {$[\%]$} & $1.5-2.4$ & 1.8 \\
\hline Magnesium (as $\mathrm{Mg})$ & {$[\%]$} & $1.4-2.2$ & 1.8 \\
\hline Iron (as Fe) & {$[\%]$} & Max. 0.1 & 0.04 \\
\hline Sulphur (as S) & {$[\%]$} & Max. 8.0 & 6.0 \\
\hline Reductive substances & & Max. 25.0 & 22.0 \\
\hline Colour & - & Brown & Brown \\
\hline Water-insoluble & {$[\%]$} & Max. 0.20 & 0.15 \\
\hline Density & {$[\mathrm{g} / \mathrm{cm} 3]$} & $0.37-0.41$ & 0.40 \\
\hline & & &
\end{tabular}

\subsection{Blends of CRclay and CLS}

CR-Clay was firstly mixed with two different mass percentages of CLS to clay: $3 \%$ (Clay $+3 \%$ CLS) and $5 \%$ (Clay $+5 \%$ CLS). The mixtures were wetted to the desired water content and stored in an airtight container for at least twenty-four hours to homogenize the moisture content. Finally, samples were statically compacted to a standard Proctor compaction procedure (ASTM D698) to select the initial densities and water contents for the tests. Table 3 shows the maximum dry density $\left(\gamma_{\mathrm{dmax}}\right)$ and $95 \%$ of the maximum dry density $\left(\gamma_{\mathrm{d} 95 \%}\right)$.

Table 3: Proctor Standard results.

\begin{tabular}{|c|c|c|c|c|c|}
\hline & & & Clay & $\begin{array}{c}\text { Clay + } \\
3 \% \text { CLS }\end{array}$ & $\begin{array}{c}\text { Clay + } \\
5 \% \text { CLS }\end{array}$ \\
\hline \multirow{5}{*}{ 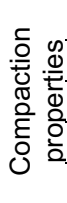 } & $\gamma_{\mathrm{dmax}}$ & {$\left[\mathrm{kN} / \mathrm{m}^{3}\right]$} & 13.0 & 12.4 & 12.5 \\
\hline & $\gamma_{\mathrm{d} 95 \%}$ & {$\left[\mathrm{kN} / \mathrm{m}^{3}\right]$} & 12.4 & 11.8 & 11.9 \\
\hline & $\omega_{\text {dry }}$ & [\%] & 18.0 & 28.0 & 27.0 \\
\hline & $\omega_{\mathrm{opt}}$ & [\%] & 31.0 & 34.0 & 35.0 \\
\hline & $\omega_{\text {wet }}$ & [\%] & 37.0 & 40.0 & 44.0 \\
\hline
\end{tabular}

\section{Methods}

The behavior of compacted samples upon wetting was measured in an oedometer apparatus. The expansiveness capacity of the soil is the increment of the height of the samples. The test consists of flooding a sample of $18 \mathrm{~mm}$ height and $76 \mathrm{~mm}$ diameter with deionized water while measuring its height variation.

The pore size distributions of the compacted specimens were characterized through mercury intrusion porosimetry (MIP) according to ASTM 2873 in a Pascal 440 Thermo Fisher, for measuring pores size between $7 \mathrm{~nm}$ to $13000 \mathrm{~nm}$, and Pascal 140 Thermo Scientific, for measuring pores size between $13000 \mathrm{~nm}$ to $100000 \mathrm{~nm}$. The morphology of the samples was studied using scanning electron microscopy (SEM) within a PhenomWorld ProX. For SEM images, small samples portions were mounted on aluminium stubs with carbon coating to ensure conductivity through the sample. The detail procedures followed is in Fernandez et al. [13].

For determining soil suction, the filter paper method test was used, according to ASTM D5298. The procedure 
consists in measuring the moisture content of a calibrated filter paper in contact with soil (matric suction) or in equilibrium with the partial vapour pressure in a sealed container with no more than $1^{\circ} \mathrm{C}$ temperature fluctuation (total suction). Samples require a minimum of seven days to reach a hygroscopic balance between the filter paper and the soil mixtures. A precision weighing balance is used to measure the moisture content of the filter paper. The ASTM standard proposes the calibration of the gravimetric water contents of the filter paper Whatman No. 42 and suction measured adopted for this study.

The procedures for measuring the matric and total suction consists of preparing two soil specimens of $100 \mathrm{~mm}$ diameter and $25 \mathrm{~mm}$ height. A set of three filter papers between both compacted samples are to measure the matrix suction. The filter papers in contact with the samples have a larger diameter $(100 \mathrm{~mm})$, while the one in the middle has a smaller one $(90 \mathrm{~mm})$. The smaller filter paper is subtracted quickly, and the increase of its weight registered. In this series of tests, the filter papers were previously oven-dried. The total suction was measured, placing two extra sets of filter paper over the upper soil sample avoiding contact between the specimens. The sets were placed in a sealed container to gain a moisture equilibrium for seven days before measuring the moisture of the filter papers. Compacted samples were prepared to start from different water content with a targeted dry density.

There is a link between the water retention curve (WRC) and the pore size distribution (PSD) of a soil sample obtained with MIP. The interface between the nonwetting fluid (air in case of WRC or liquid $\mathrm{Hg}$ in case of MIP) and the wetting fluid (water and air, in case of WRC or Hg vapour for MIP) is governed mainly by capillarity. MIP can be related to the drying path of the initially saturated sample by applying an increase of external air pressure (non-wetting fluid) [17,18]

\section{Experimental results and discussion}

The swelling capacity was qualitatively determined by immersing compacted CR-Clay in a beaker with water, as is shown in Figure 1. The sample was utterly disintegrated two days after being submerged into distilled water. Hence, its volume was approximately doubling laterally and vertically. A series of samples were subjected to wetting path in an oedometer to evaluate expansion capacity. The free swell of the untreated Clay was $32 \%$. Clay with $3 \%$ and $5 \%$ of CLS presented a reduction of the free swelling of $40 \%$ and $45 \%$ respectively. This result confirms that CLS reduces the swelling capacity of Clay $[2,11]$. Alazigha et al. [2] observed that the reduction in the expansiveness of a CLS treated sample is due to the binding of soil minerals due to CLS through basal and peripheral absorption. The CLS absorption restricts the infiltration of moisture into the soil and reduces the free swelling. The swelling reduction for higher CLS dosages does not present a linear trend. The low permeability of the CR-Clay fulfils an essential role in the time evolution of expansiveness (Marti et al. [19], Piqué et al. [20]). In general, the CR-clay activation requires several days to increase free swelling as is shown in Figure 2. This result is following similar behaviour regional clayey soils (Manzanal et al. [16]).

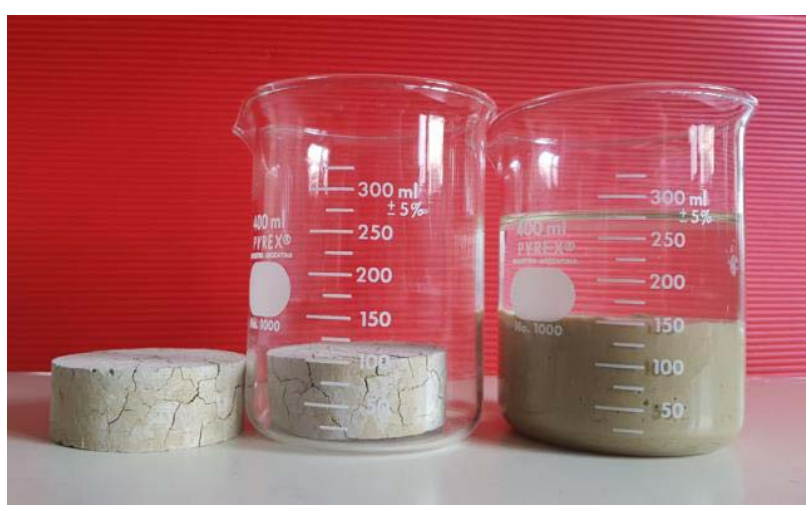

Fig. 1. Image of CR-Clay previous to be submerged and two days after be submerged into distilled water

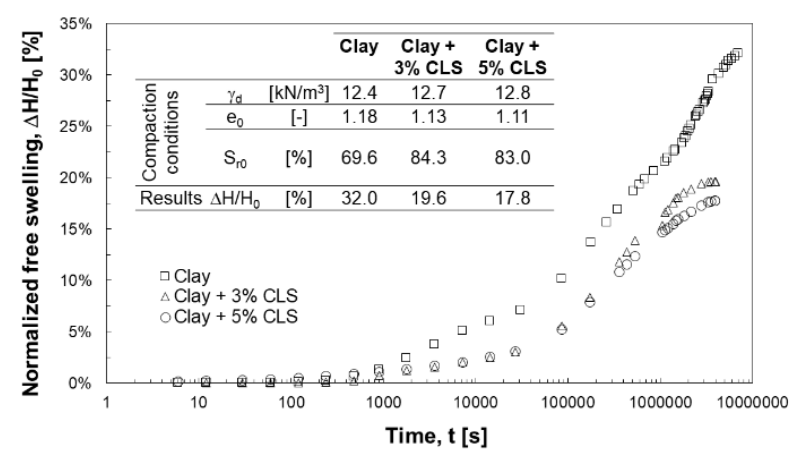

Fig. 2. Free swell evolution with time for the three mixtures: Clay, Clay $+3 \%$ CLS and Clay $+5 \%$ CLS compacted samples at a given dry density $(\mathrm{e}=1.18-1.23)$.

\subsection{CLS-Clay sample microstructure}

Figures 3 and 4 show the pore size distribution curves of Clay and Clay + CLS. Graphs are presented in terms of both density functions and cumulative intruded void ratio where the intruded pore radius is represented on the logarithmic scale $x$-axis. The pore size density distribution presented in Figure 3 shows two dominant pore size on the dry of optimum moisture content ( $\square$ opt) for Clay and Clay + CLS as obtained by different authors (Romero, 2011; Alonso et al. 2013). These two dominant pore sizes are referred to as micro-porosity ( 7 to $80 \mathrm{~nm}$ approximately) and macro-porosity (7000 to $70000 \mathrm{~nm}$ ). Regarding the micro-porosity, it is noted that the most frequent microstructural pore size of Clay is more significant than the most frequent microstructural pore size of both Clay $+3 \%$ CLS and Clay $+5 \%$ CLS. This can be related to a microstructural void ratio reduction with the CLS addition as it showed a significant decrease of both cation exchange capacity and specific surface for both studied samples. Indraratna et al. (2010) proposed a stabilization mechanism in which CLS formed a chain that entered between clay particles, neutralizing electric charges of the surface of the clay, holding the clay particles together. The neutralization of electric charges in clay surface reduce the repulsive forces between clay 
particles. This effect can be related to the microporosity decrease.

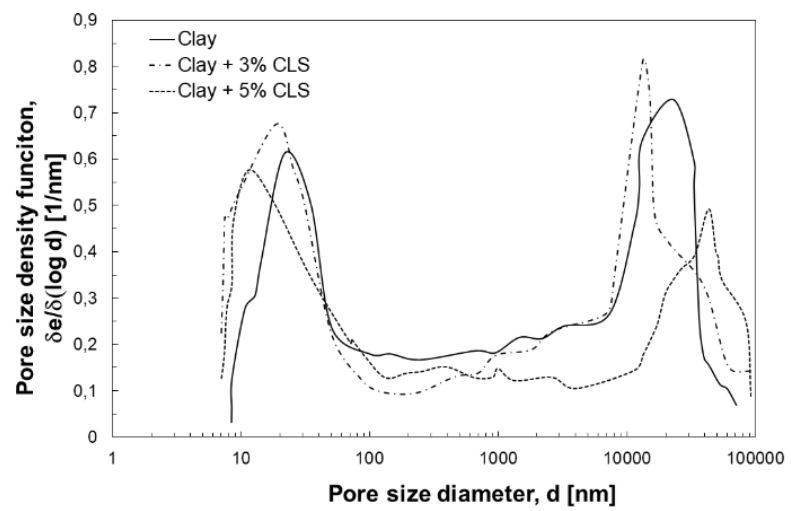

Fig. 3. Pore size density distribution for the three mixtures obtained by MIP for Clay, Clay $+3 \%$ CLS and Clay $+5 \%$ CLS compacted samples at dry of optimum water content $(\mathrm{Sr}=41 \%$ $-46 \%)$ and a given dry density $(\mathrm{e}=1.18-1.23)$.

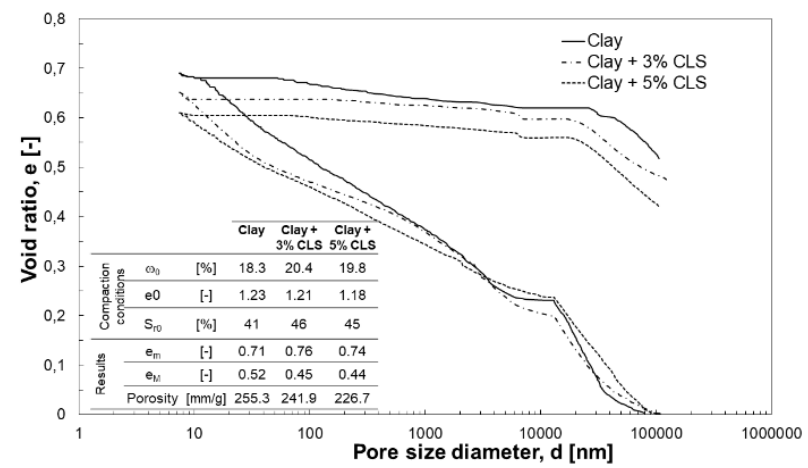

Fig. 4. Evolution of intruded void ratio obtained by MIP for the three mixtures: Clay, Clay $+3 \%$ CLS and Clay $+5 \%$ CLS compacted samples at dry of optimum water content $(\mathrm{Sr}=41 \%$ $-46 \%)$ and a given dry density $(e=1.18-1.23)$.

Regarding the macro-porosity, Clay $+3 \%$ CLS mixture had the smallest pore characteristic size, followed by the untreated Clay and Clay $+5 \%$ CLS mixtures respectively. However, considering the void ratio, it is noted that CLS reduced the porosity in 5\% for Clay $+3 \%$ CLS and $11 \%$ for Clay $+5 \%$ CLS as can be observed in Figure 4. The micro and macro-structural void ratio portions can be obtained according to Delage and Lefebvre [21] throughout the intrusion and extrusion on MIP. These authors defined micro-porosity as the reversible portion of mercury extruded from the samples when the pressure of mercury is diminished (Figure 4). This is related to the microstructural configuration of the sample, the surface charges of clay platelets and the non-wettability of mercury. The macro-porosity portion of the sample is the non-reversible mercury volume stacked in the sample. The macro void ratio is calculated as the initial void ratio minus the micro void ratio, which is the last registered void ratio of the test. The results showed that the macro void ratio decreased with the addition of CLS, $e_{M}=0.52$ for Clay, $e_{M}=0.45$ for Clay $+3 \%$ CLS and $e_{M}=0.44$ for Clay $+5 \%$ CLS.

The decrease in the pore volume due to CLS can be observed on SEM images of compacted samples with different percentages of CLS with moisture content at dry of optimum $\left(\omega_{\text {dry }}\right)$ (Figure 5a) and wet of optimum $\left(\omega_{\text {wet }}\right)$ (Figure 5b).

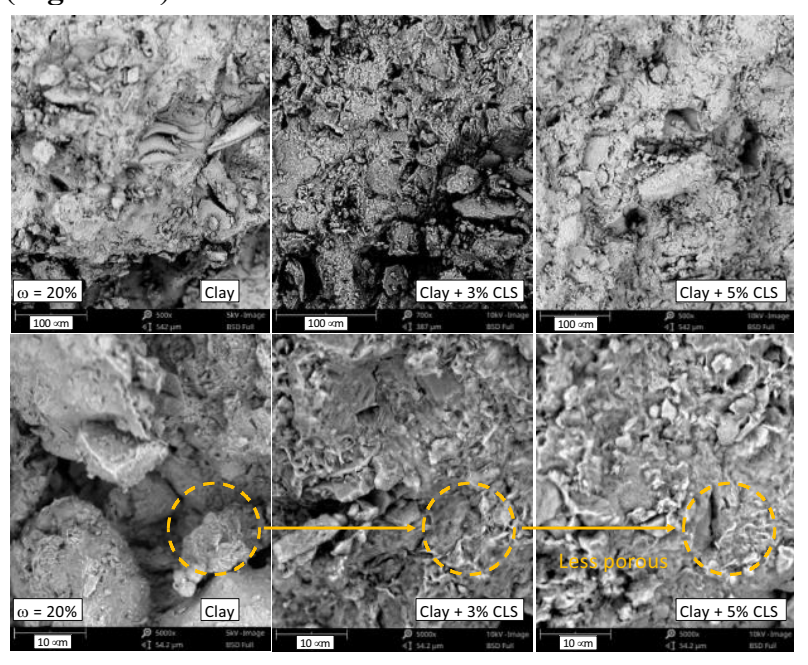

Fig. 5a. SEM for Clay, Clay $+3 \%$ CLS and, Clay $+3 \%$ CLS dry of optimum $(\omega=20 \%)$.

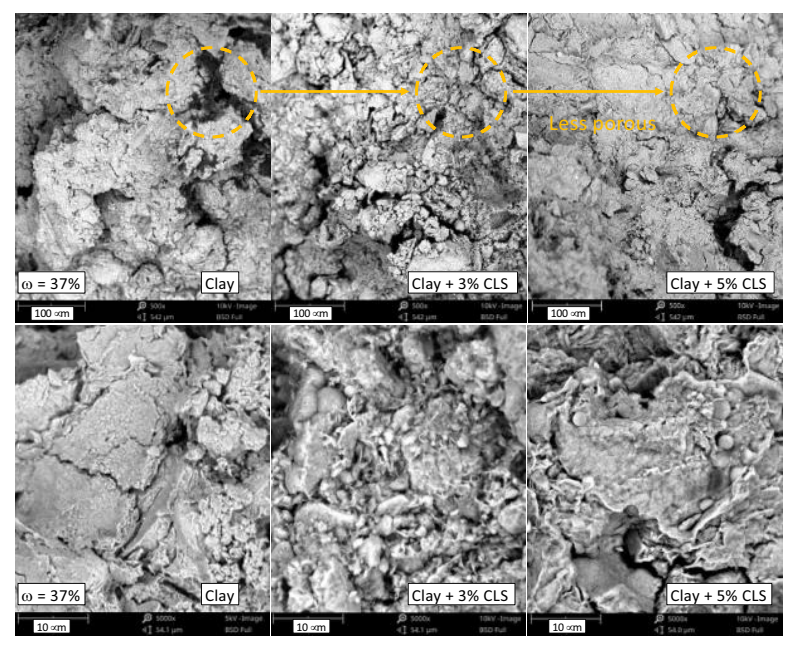

Fig. 5b. SEM for Clay, Clay + 3\% CLS and, Clay + 3\% CLS wet of optimum $(\omega=37 \%)$.

\subsection{Soil-Water Retention Curve}

The water retention capacity of the unsaturated compacted samples of Clay and Clay + CLS were obtained using the filter paper method (ASTM D5298). This technique allows estimating the relationship between the degree of saturation and suction at equilibrium for compacted samples at a given density and different initial water content of Clay, Clay $+3 \%$ CLS and Clay $+5 \%$ CLS. Experimental results are presented in Figure 6 in terms of suction and degree of saturation. The samples had an average dry density of $12.4 \mathrm{kN} / \mathrm{m}^{3}$ ( $\mathrm{e}=1.130$ $1.250)$, except for Clay $+3 \%$ CLS - UNPSJB samples with slightly higher average densities $(e=0.750-0.940)$. Clay + CLS presented fairly scattered results for the same dry density. For a certain degree of saturation, it is 
observed that the estimated suctions of Clay with 3.0\% and $5.0 \%$ of CLS are larger than Clay. However, the estimated suction increment with the increase in the CLS dosage is rather small.

Results were modelled with the van Genuchten equation (van Genuchten, [22]). Equation (1) describes the soilwater retention curve. This equation relates the matric suction $\left(\mathrm{u}_{\mathrm{a}}-\mathrm{u}_{\mathrm{w}}\right)$ and the degree of saturation of the sample $\left(\mathrm{S}_{\mathrm{r}}\right)$. The effective degree of saturation $\left(\mathrm{S}_{\mathrm{e}}\right)$ varies from 0 to 1 . It equals unity when samples are saturated, even for matric suctions bigger than 1 . The value of suction in which desaturation begins is called air-entry value suction $\left(\mathrm{S}_{\mathrm{ae}}\right) . \mathrm{S}_{\mathrm{e}}$ equals zero when the residual degree of saturation $\left(S_{\text {res }}\right)$ is reached. $S_{\text {res }}$ is the approximately constant value of the degree of saturation regardless of the increasing matric suction. This residual water content is trapped in the microstructure of the soil. Therefore, residual degree of saturation or residual water content is related to the microporosity of the sample obtained within mercury intrusion porosimetry (MIP) (Romero, 1999). Finally, $\lambda$ is a fitting parameter that considers the pore size distribution of the soils. For more aggregated or coarse-grained soils, $\lambda$ is expected to be higher.

$$
S_{e}=\frac{S_{r}-S_{\text {res }}}{S_{\text {sat }}-S_{\text {res }}}=\left\{1+\left[\frac{u_{a}-u_{w}}{S_{a e}}\right]^{1 / 1-\lambda}\right\}^{-\lambda}
$$

The water retention curves fitted with the experimental data and the van Genuchten parameters are shown in Fig.6. The results of the calibration suggest that CLS change the air entry value $\left(\mathrm{S}_{\mathrm{ae}}\right)$ from $300 \mathrm{kPa}$ to $600 \mathrm{kPa}$ when the CLS addition is 5\%. This value is related to the suction that air must exceed to enter the pores of the soil, leading to the beginning of desaturation. MIP results showed that the addition of $5 \%$ of CLS to Clay reduced the frequency of large pores with an overall reduction of macro void ratio, which is consistent with the increment of the air-entry value $\left(\mathrm{S}_{\mathrm{ae}}\right)$ of Clay $+5 \%$ CLS.

There is a slight decrease of $\lambda$ (van Genuchten pore distribution parameter) with the addition of CLS, which agrees with the reduction in porosity observed in MIP performed on samples with an initial degree of saturation of $45 \%$.

Romero [17]) related the residual water content (or the residual degree of saturation) to the difference between the void ratio measured through the intrusion of mercury during MIP test and the overall soil void ratio obtained from the compaction characteristics (dry density and water content). This difference would be the non-intruded void ratio $\Delta \mathrm{e}_{\mathrm{ni}}$. The residual water content is 100 . $\Delta \mathrm{e}_{\mathrm{ni}} / G_{s}$.

Figure 7 shows MIP results as a function of water content and suction together with the discrete results obtained by the filter paper technique. The residual water content obtained with MIP for the three samples analysed (Clay, Clay $+3 \%$ CLS, Clay $+5 \%$ CLS) varies from $20.0 \%$ to $21.3 \%$. The residual water content is not affected by the addition of CLS. The degree of residual saturation associated with these water contents and their respective void ratios vary between $44 \%$ and $48 \%$. These results appear to be high, assuming that soils that contain a significant fraction of smectite cannot be fully intruded by mercury at $200 \mathrm{MPa}$ (p.e.Castelblanco et al., 2012). This circumstance is directly related to the fact that the evolution of the void ratio curve maintains a slope in the area of the smallest pores (Figure 4). Therefore, there is a difference between the intruded void ratio and the overall soil void ratio. In this case, the smallest value reached with the MIP at $200 \mathrm{MPa}$ is $7.4 \mathrm{~nm}(74 \AA)$. Since the basic constituent of Clay is the elementary clay layer (9.6 $\AA$ thick for smectite), there might be several pores that were not intruded by the mercury [23].

In literature, there is some controversy when considering the residual saturation degree as a physical parameter (e.g. Luckner et al., [24]) or a calibration parameter (e.g. Fredlund \& Xing [25], Manzanal et al., [26,27]). In this work, the value was adopted according to the results obtained with MIP following the procedure of Romero (1999) and using the calibration of the experimental results obtained by the filter paper method. Figure 6 shows the experimental results with the van Genutchen model with the residual saturation degree for all samples equal to $30 \%$. The samples used for the calibration of the van Genuchten model had a void ratio varying from $\mathrm{e}=$ $1.130-1.250$

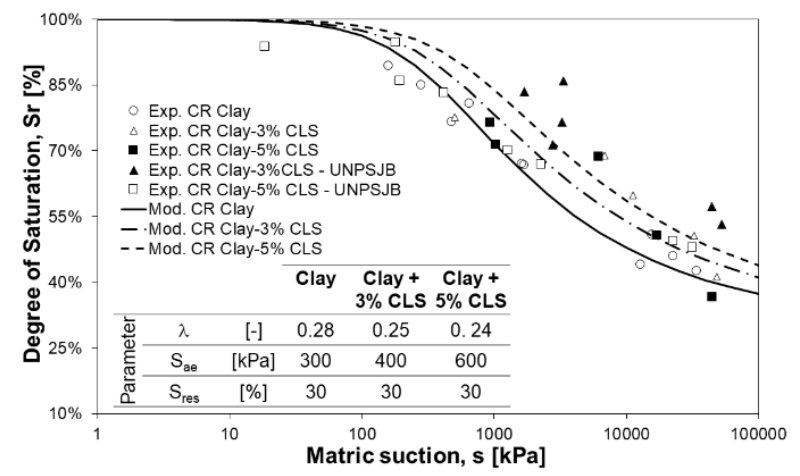

Fig. 6. Relation of suction and degree of saturation using the filter paper technique and van Genuchten model for water retention curve for the three mixtures: Clay, Clay $+3 \%$ CLS and Clay $+5 \%$ CLS.

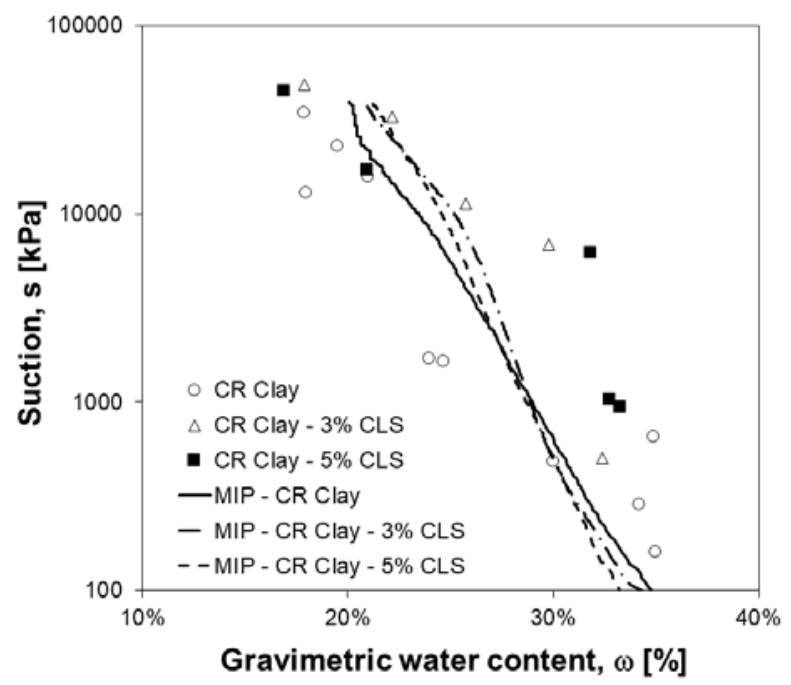

Fig. 7. Comparison of gravimetric water content and degree of saturation using the filter paper technique with MIP results for the three mixtures: Clay, Clay $+3 \%$ CLS and Clay $+5 \%$ CLS. 


\section{Conclusion}

The paper studied the interaction of CR-Clay and CLS throughout a series of tests for characterizing the physical properties, the microporosity, the WRC and the variation of the swelling capacity of the three compacted mixtures: a natural clay (CR-Clay), the CR-Clay with 3\% and 5\% of CLS. Results showed significant changes in the physical and engineering properties.

The addition of $3.0 \%$ and $5.0 \%$ of CLS reduced the swelling capacity of CR-Clay from $32.0 \%$ to $19.6 \%$ and $17.8 \%$, respectively.

CR-Clay- CLS admixture showed lower porosity or less connected porous arrangement. The mercury intrusion porosimetry registered a reduction of intruded void ratio with the addition of CLS.

The addition of CLS increased the estimated suction for a given degree of saturation. However, the increment of suction with CLS dosage increase is relatively small. Results suggested that the addition of $5 \%$ of CLS changes the air entry value ( $\mathrm{Sae}$ ) of the van Genuchten model from $300 \mathrm{kPa}$ to $600 \mathrm{kPa}$. This increment, which is consistent with the MIP results, showed that the addition of $5 \%$ of CLS reduced the frequency of large pores with an overall reduction of macro void ratio. The parameter $\lambda$ from the van Genuchten model slightly decreased with the addition of CLS due to a decrease of the pore size distribution is reduced, as the MIP results showed. The CLS addition does not influence the residual degree of saturation evaluated within MIP.

Results showed that CLS yield acceptable performance as a soil stabilizer, particularly in reducing the natural Clay's swell potential even with no curing time. Further research is required to ensure its effectiveness on long-term behaviour, particularly after cyclic wetting-drying and cyclic freeze-thaw and the impact on longer curing times in experimental results. Moreover, the environmental impact (leachability) requires more research. Finally, constructability and cost-efficiency comparison is encouraged between CLS and traditional additives, bearing in mind the environmental costs of each additive.

\section{Acknowledgements}

The authors acknowledged the financials support of Universidad Nacional de la Patagonia San Juan Bosco (Project UNPSJBSYT PI1364) and Secretaría de Políticas Universitarias (MEYD-SPU) (Project "Agregando Valor 2017 - Fundaciones Sustentables" RESOL-2017-5157APN-SECPU\#ME), and the personal of LISHA (Laboratorio de investigación de Suelos, Hormigones y Asfaltos).

\section{References}

1. L. Hoyos, A. Puppala, P. Chainuwat (2004). Dynamic properties of chemically stabilized sulfate rich clay. Journal of Geotechnical and Geoenvironmental Engineering. 130: 153-162. DOI: 10.1061/(ASCE)1090-0241(2004)130:2(153).
2. D. P. Alazigha, B. Indraratna, J. S. Vinod, \& L.E Ezeajugh. (2016). The swelling behaviour of lignosulfonate-treated expansive soil. Proceedings of the Institution of Civil Engineers: Ground Improvement, $\quad \mathbf{1 6 9}(3), \quad 182-193$. https://doi.org/10.1680/jgrim.15.00002

3. I. Chang, G. Cho (2012). Strengthening of Korean residual soil with $\beta-1, \quad 3 / 1, \quad 6$-glucan biopolymer. Const. Build. Mater. 30: 30-35.

4. N. Hataf, P. Ghadir, N. Ranjbar (2018). Investigation of soil stabilization using chitosan biopolymer. J. Clean. Prod. 170: 1493-1500.

5. R. Brooks (2009). Soil stabilization with fly ash and rice husk ash. International Journal of Research and Reviews in Applied Sciences. 1(3), 209-217.

6. H. Canakci, A. Aziz, F. Celik (2015). Soil stabilization of clay with lignin, rice husk powder and ash. Geomechanics and Engineering. 8(1), 67-79. doi: 10.12989/gae.2015.8.1.067

7. S. Orlandi, M.E. Taverna, Y. Villada, T. Piqué, C. Laskowski, V. Nicolau, D. Estenoz, D. Manzanal (2021). Additives based on vegetable biomass to improve the stabilization of expansive clay Soil. Environmental Geotechnics. Accepted.

8. M. Attom, \& M. Al-Sharif (1998). Soil stabilization with burned olive waste. App. clay Sci. 13(3), 219230 .

9. J. Tingle, J. Newman, S. Larson, C. Weiss, J. Rushing (2007). Stabilization mechanisms of nontraditional additives. Transp. Res. Rec. 1989(1), 59-67.

10. N. Ijaz \& F. Dai (2020). Paper and wood industry waste as a sustainable solution for environmental vulnerabilities of expansive soil: A novel approach. Journal of Environmental Management. 262 (January), 110285.

Doi:10.1016/j.jenvman.2020.110285

11. D. P. Alazigha, B. Indraratna, J. S. Vinod \& A. Heitor (2018). Mechanisms of stabilization of expansive soil with lignosulfonate admixture. Transportation Geotechnics. $\quad \mathbf{1 4 : 8 1 - 9 2 . ~}$ Doi:10.1016/j.trgeo.2017.11.001.

12. M. Fernandez, D. Manzanal, T. Piqué, M. Codevilla (2017). Polymer Applications to Control Soil Expansion. Second International Symposium on Coupled Phenomena in Environmental Geotechnics (CPEG2). Faculty of Engineering, University of Leeds, LEEDS, LS2 9JT, UK. September 6-7, 2017

13. M. Fernandez, S. Orlandi, T. Piqué, M. Codevilla, D. Manzanal (2021. Performance of Calcium Lignosulfonate as stabilizer of highly expansive clay. Transportation Geotechnics. Vol. 27:100469. https://doi.org/10.1016/j.trgeo.2020.100469.

14. S. Orlandi, D. Manzanal, A. Ruiz, M. Ávila, V. Graf, (2015). A case study on expansive clays on Comodoro Rivadavia city. From Fundamentals to Applications in Geotechnics: Proceedings of the 15th Pan-American Conference on Soil Mechanics and 
Geotechnical Engineering (15th PCSMGE), Manzanal D. \& Sfriso A. Editors. 15-17 November, Buenos Aires, Argentine. Ed. IOS Press. Pages 2276 - 2283. doi: 10.3233/978-1-61499-603-3-2276.

15. S. Orlandi, D. Manzanal, E. Miranda, M. Robison (2019) Using Lignin as stabilizer of swelling soils. XVI Pan-American Conference on Soil Mechanics and Geotechnical Engineering. 17-20 November 2019. Cancun, México. Doi: 10.3233/STAL190295

16. D. Manzanal, S. Orlandi, E. Miranda, M. Robinson, J. C. Barría (2019). Swell characterization of expansive clays from Comodoro Rivadavia city. Argentine. XVI Pan-American Conference on Soil Mechanics and Geotechnical Engineering. 17-20 November 2019. Cancun, México. Doi:10.3233/STAL190107

17. E. Romero (1999). Characterization and thermohydro-mechanical behaviour of unsaturated Boom clay: an experimental study. PhD thesis, Universitat Politecnica de Catalunya, Barcelona.

18. J.A.Muñoz-Castelblanco, J. Pereira, P. Delage, Y. Cui (2012). The water retention properties of a natural unsaturated loess from northern France. Geotechnique, 62(2), pp. 95-106. DOI: 10.1680/geot.9.P.084.

19. L. Marti, M. Codevilla, T. Piqué, D. Manzanal (2015). Natural Soil Modified with Polymer for use in landfill systems. From Fundamentals to Applications in Geotechnics (15th PCSMGE). Manzanal D. \& Sfriso A. Editors. 15-17 November, Buenos Aires, Argentine. Ed. IOS Press. Pages 2228 - 2235. doi: 10.3233/978-1-61499-603-3-2228

20. T. Piqué, D. Manzanal, M. Codevilla, S. Orlandi (2019). Polymer Enhanced Soils Mixture for Potential Use as Covers or Liners in Landfill Systems Environmental Geotechnics. Published Online: August 23, 2019. DOI: 10.1680/jenge.18.00174

21. P. Delage \& G. Lefebvre (1984). Study of the Structure of a sensitive Champlain clay and of its evolution during consolidation. Canadian Geotechnical Journal. Vol. 21(1):21-35. DOI: 10.1139/t84-003

22. M.T. van Genuchten (1980). A Closed-form Equation for Predicting the Hydraulic Conductivity of Unsaturated Soils. Soil Science of America Journal. 44: 892-898.

23. P. Delage, D. Marcial, Y. Cui, X. Ruiz (2006). Ageing effects in a compacted bentonite: a microstructure approach. Geotechnique 56, No. 5, 291-304, DOI: 10.1680/geot.2006.56. 5.291

24. L. Luckner, M.T. Van Genuchten, D.R. Nielsen, ( 1989). A consistent set of parametric models for the two-phase flow of immiscible fluids in the subsurface. Water Resour. Res. 25(10), 2187-2193, DOI:10.1029/WR025i010p02187

25. D.G. Fredlund \& A. Xing (1994). Equations for the Soil-Water Characteristic Curve. Canadian Geotechnical Journal. 31, 521-532.
26. D. Manzanal, M. Pastor, J.A. Fernandez Merodo,P. Mira (2010). A state parameter based Generalized Plasticity model for unsaturated soils. Computer Modelling in Engineering and Science CMES, vol. 55, no.3, pp.293-317, 2010. Doi: 10.3970/cmes.2010.055.293

27. D. Manzanal, M. Pastor, J.A. Fernandez Merodo (2011). Generalized plasticity state parameter-based model for saturated and unsaturated soils Part II: unsaturated soil modeling. Int. J. Numer. Anal. Met. 35 (18), 1899-1917. https://doi.org/10.1002/nag.983 